\title{
Bifunctional drugs for the treatment of asthma and chronic obstructive pulmonary disease
}

\author{
Clive Page ${ }^{1}$ and Mario Cazzola ${ }^{2}$
}

\author{
Affiliations: \\ 'Sackler Institute of Pulmonary Pharmacology, Institute of Pharmaceutical Science, King's College London, \\ London, UK. \\ 'Unit of Respiratory Clinical Pharmacology, Dept of System Medicine, University of Rome "Tor Vergata", Rome,
} Italy.

Correspondence: Clive Page, Sackler Institute of Pulmonary Pharmacology, Institute of Pharmaceutical Science, King's College London, 150 Stamford Street, London SE1 9NH, UK.

E-mail: clive.pageakcl.ac.uk

\begin{abstract}
Over the last decade, there has been a steady increase in the use of fixed-dose combinations of drugs for the treatment of a range of diseases, including hypertension, cancer, AIDS, tuberculosis and other infectious diseases. It is now evident that patients with asthma or chronic obstructive pulmonary disease (COPD) can also benefit from the use of fixed-dose combinations, including combinations of a long-acting $\beta_{2}$-agonist and an inhaled corticosteroid, and combinations of long-acting $\beta_{2}$-agonists and long-acting muscarinic receptor antagonists. In fact, there are now a number of "triple-inhaler" fixed-dose combinations under development, with the first such triple combination having been approved in India. This use of combinations containing drugs with complementary pharmacological actions in the treatment of patients with asthma or COPD has also led to the discovery and development of drugs having two different primary pharmacological actions in the same molecule, which we have called "bifunctional drugs". In this review, we discuss the state of the art of these new bifunctional drugs as novel treatments for asthma and COPD that can be categorised as bifunctional bronchodilators, bifunctional bronchodilator/antiinflammatory drugs and bifunctional anti-inflammatory drugs.
\end{abstract}

0

@ERSpublications

Bifunctional drugs offer an exciting new approach to the treatment of asthma and COPD http://ow.ly/uw5zW

Received: Jan 062014 | Accepted after revision: March 042014 | First published online: April 22014

Conflict of interest: Disclosures can be found alongside the online version of this article at erj.ersjournals.com 


\section{Background}

Asthma and chronic obstructive pulmonary disease (COPD) are common complex inflammatory diseases of the respiratory tract that often require treatment with multiple drug classes $[1,2]$. Over the last decade, there has been a steady increase in the use of fixed-dose combinations of two or more drugs for the treatment of a range of conditions including hypertension [3], cancer [4], AIDS [5], tuberculosis [6] and other infectious diseases [7].

It is now clear that the treatment of asthma and COPD can also benefit from the use of fixed-dose combinations of two or more drugs [8]. Today, the treatment of asthma and COPD globally is dominated by the use of inhaled fixed-dose combinations of a long-acting $\beta_{2}$-agonist (LABA) and an inhaled corticosteroid (ICS). Inhaled fixed-dose combinations of both short-acting $\beta_{2}$-agonists (SABAs) and shortacting muscarinic receptor antagonists (SAMAs), as well as LABAs and long-acting muscarinic antagonists (LAMAs) are also widely used as bronchodilators for the treatment of patients with COPD and more severe asthma. Indeed, there is now a number of inhaled medicines in development containing various combinations of three of these pharmacological classes, so-called triple inhalers [9-11].

These developments in treatment reflect our growing understanding that there is a need to treat both the underlying inflammation and the symptoms of airway obstruction that characterise these conditions. Moreover, the use of multiple drugs in a single inhaler is thought to improve adherence to treatment, as it is well recognised that patients prescribed a bronchodilator and an anti-inflammatory drug as monoinhalers will often stop the anti-inflammatory drug when symptoms improve [12], despite current understanding suggesting that regular use of ICS (at least in patients with asthma) may be necessary to optimise lung function and reduce exacerbations of the disease in the long term [13].

However, the development of formulations to allow the use of more than one drug class in a single inhaler is sometimes challenging, as there are often differences in duration of action of the monocomponents and issues concerning chemical compatibility and stability, as well as galenic challenges relating to the different physiochemical properties of the different drug classes [8]. This is especially so with the development of triple inhalers and, to date, only one such medicine, containing tiotropium bromide, ciclesonide and formoterol fumarate, has been approved, but only in India [11]. However, at present, there is very little information in the scientific literature supporting the use of triple therapy.

An alternative approach to delivering complementary pharmacological activities for the treatment of patients with asthma or COPD is to develop molecules specifically designed to have two distinct primary pharmacological actions based on distinct pharmacophores, which we will term bifunctional drugs. These are not to be confused with drugs that can exhibit multiple mechanisms of action that may all contribute to clinical effectiveness (e.g. glucocorticosteroids, xanthines or statins) as, while it is recognised that some drugs having multiple effects have been the starting point for the development of bifunctional drugs, they were not intentionally developed to have multiple actions via distinct mechanisms. In this article, we have therefore concentrated on reviewing the current status of bifunctional drugs specifically designed to have two mechanisms of action in the same molecule that are in development for the treatment of asthma and/or COPD (table 1).

\section{Bifunctional bronchodilator drugs}

It has long been recognised that $\beta_{2}$-agonists and muscarinic receptor antagonists improve lung function by distinct pharmacological mechanisms, $\beta_{2}$-agonists acting to relax airway smooth muscle irrespective of the cause of the bronchoconstriction and muscarinic receptor antagonists by blocking $\mathrm{M}_{3}$ receptors on airway smooth muscle to limit the actions of the neurotransmitter acetylcholine (ACh) released from parasympathetic nerves innervating the lung [14].

Moreover, $\beta_{2}$-agonists can amplify the bronchial smooth muscle relaxation directly induced by the muscarinic antagonist by decreasing the release of ACh via a modulation of cholinergic neurotransmission that involves calcium-activated potassium $\left(\mathrm{K}_{\mathrm{Ca}}\right)$ channels rather than adenylyl cyclase and subsequent increases in intracellular levels of cAMP. Activation of $\mathrm{K}_{\mathrm{Ca}}$ channels is thought to hyperpolarise the cell membrane, thus causing reductions in the concentration of intracellular calcium and ACh release in prejunctional parasympathetic nerves $[14,15]$, and thus potentially providing additional bronchodilation above the effects seen with antagonism of muscarinic receptors on the airway smooth muscle. However, this mechanism seems unlikely to contribute in a significant way in practice as there is evidence clearly indicating that $\beta_{2}$-agonists facilitate, rather than inhibit, parasympathetic ACh release in the airways $[16,17]$. Therefore, it has been suggested that crosstalk between muscarinic receptors and $\beta_{2}$-adrenoceptors, leading to greater functional antagonism at the level of the airway smooth muscle, may be of more importance in providing any additional bronchodilation when both classes of drug are used together $[16,17]$. In effect, crosstalk between $\mathrm{G}_{\mathrm{q}}$-coupled $\mathrm{M}_{3}$ receptors and $\mathrm{G}_{\mathrm{s}}$-coupled $\beta_{2}$-adrenoceptors may have a 
TABLE 1 Bifunctional drugs that have been evaluated or are under development for treating asthma and/or chronic obstructive pulmonary disease

\begin{tabular}{|c|c|c|c|}
\hline Class/agent & Stage of development & Pros & Cons \\
\hline $\begin{array}{l}\text { MABAs } \\
\text { GSK961081 } \\
\text { AZD2115 } \\
\text { LAS190792 } \\
\text { THRX200495 } \\
\text { TEI3252 } \\
\text { PF3429281 } \\
\text { PF4348235 }\end{array}$ & $\begin{array}{l}\text { Phase III } \\
\text { Phase II } \\
\text { Phase I } \\
\text { Preclinical } \\
\text { Preclinical } \\
\text { Discontinued } \\
\text { Discontinued }\end{array}$ & $\begin{array}{l}\text { Enhanced patent position } \\
\text { A single molecule that confers both therapeutic } \\
\text { effects can avoid the approval of each } \\
\text { component separately as well as in } \\
\text { combination, and may be a faster and less } \\
\text { expensive route to regulatory approval } \\
\text { They offer the benefit of delivering a fixed ratio } \\
\text { into every region of the lung reducing the } \\
\text { complexity of combination inhalers, a single } \\
\text { pharmacokinetic profile, a uniform ratio of } \\
\text { activities at the cellular level and a simplified } \\
\text { clinical development programme } \\
\text { As MABAs offer benefits in terms of ease-of-use, } \\
\text { convenience and, consequently, compliance, } \\
\text { adherence to the prescribed treatment, would } \\
\text { probably be improved } \\
\text { Patients cannot take one agent without taking } \\
\text { the other }\end{array}$ & $\begin{array}{l}\text { The ratio of muscarinic antagonism and } \\
\beta_{2} \text {-agonism activities cannot be adjusted } \\
\text { as needed and this limits dosing flexibility } \\
\text { The combination of muscarinic antagonism } \\
\text { and } \beta_{2} \text {-agonism activities might } \\
\text { theoretically cause a downregulation of } \\
\beta_{2} \text {-adrenoceptors and an upregulation of } \\
\text { muscarinic acetylcholine receptors } \\
\text { Not clear whether the drug should be dosed } \\
\text { for the } \beta_{2} \text { agonist activity or the } \\
\text { muscarinic receptor antagonist activity }\end{array}$ \\
\hline $\begin{array}{l}\text { Inhaled nitric oxide-donating analogues } \\
\text { TPI } 1020 \\
\text { NCX } 950\end{array}$ & $\begin{array}{l}\text { Discontinued } \\
\text { Discontinued }\end{array}$ & $\begin{array}{l}\text { Improved anti-inflammatory effects compared to } \\
\text { budesonide (TPI 1020) } \\
\text { Improved bronchodilator effects compared to } \\
\text { salbutamol due to the release of NO (NCX 950) }\end{array}$ & Limited clinical efficacy \\
\hline $\begin{array}{l}\text { PDE3/4 inhibitors } \\
\text { RPL554 } \\
\text { KCA-1490 }\end{array}$ & $\begin{array}{l}\text { Phase II } \\
\text { Preclinical }\end{array}$ & $\begin{array}{l}\text { The combination of both bronchodilator (PDE3 } \\
\text { mediated) and anti-inflammatory activity (PDE3 } \\
\text { and PDE4 mediated) could result in an } \\
\text { enhanced overall efficacy profile compared with } \\
\text { selective PDE4 inhibitors } \\
\text { PDE3 (which is predominantly localised to the } \\
\text { particulate cellular fraction) and PDE4 (which is } \\
\text { predominantly cytosolic) can regulate different } \\
\text { pools of cAMP }\end{array}$ & $\begin{array}{l}\text { There are concerns about the potential } \\
\text { cardiovascular toxicity of PDE3 inhibition } \\
\text { Further studies are needed to better } \\
\text { understand the full potential of this novel } \\
\text { therapy for COPD and asthma }\end{array}$ \\
\hline $\begin{array}{l}\text { Other bifunctional PDE inhibitors } \\
\text { Dual PDE4 inhibitor/ } \beta_{2} \text {-agonist } \\
\text { GS-5759 } \\
\text { Hybrids that combine both salmeterol and the } \\
\text { PDE4 inhibitors roflumilast or phthalazinone } \\
\text { Dual PDE4 inhibitor/ M3-receptor antagonist }\end{array}$ & $\begin{array}{l}\text { Preclinical } \\
\text { Preclinical }\end{array}$ & $\begin{array}{l}\text { The combination of both anti-inflammatory (PDE4 } \\
\text { mediated) and bronchodilator (mediated by } \\
\beta_{2} \text {-agonism or M3-receptor antagonism) activity } \\
\text { could result in an enhanced overall efficacy } \\
\text { profile compared with selective PDE4 inhibitors }\end{array}$ & There are very limited biological data \\
\hline $\begin{array}{l}\text { UCB-101333-3 } \\
\text { IL-4/IL-13 dual antagonists } \\
\text { Dupilumab } \\
\text { AMG } 317 \\
\text { Pitrakinra }\end{array}$ & $\begin{array}{l}\text { Phase II } \\
\text { Phase II } \\
\text { Phase II }\end{array}$ & $\begin{array}{l}\text { Reduce the IL-4-dependent rise in serum IgE, } \\
\text { and reduce IL-13-dependent BHR, lung } \\
\text { inflammation, mucin gene expression and } \\
\text { serum chitinase responses in mice } \\
\text { Might provide robust efficacy in the treatment } \\
\text { of asthma and other Th2-driven diseases }\end{array}$ & $\begin{array}{l}\text { Different studies and different agents can } \\
\text { produce different effects }\end{array}$ \\
\hline
\end{tabular}

MABA: muscarinic antagonist $/ \beta_{2}$-agonist; PDE: phosphodiesterase; IL: interleukin; BHR: bronchial hyperresponsiveness; Th: T-helper cell.

major influence on $\beta_{2}$-agonist-induced relaxation, presumably by activation of protein kinase $\mathrm{C}$ and subsequent phosphorylation of the $\beta_{2}$-adrenoceptor and/or $G_{s}$ protein that could contribute to the beneficial bronchodilatory effects of dual bronchodilator therapy [16, 17].

Endothelin (ET)-1 is a potent constrictor of airway smooth muscle and may exert various pro-fibrotic effects in the airways. Recent findings have demonstrated that human lung fibroblasts are fully able to respond to ET-1 in a functional autocrine and paracrine way, as well as expressing preproendothelin and processing this to active ET-1 [18]. Human fibroblasts also express functional ET receptors that can regulate pro-fibrotic features. Interestingly, human fibroblasts can also express both muscarinic receptors and $\beta_{2}$-receptors. As muscarinic upregulation of ET-1 contributes to profibrotic effects of muscarinic stimuli and $\beta_{2}$-agonists have been reported to inhibit the synthesis of ET-1 [19], it is plausible that LABAs and LAMAs could have a long-term benefit on ET-1 expression and thus fibrotic events, although studies have yet to be undertaken to see if this effect seen in vitro translates into a real clinical benefit.

$\beta_{2}$-agonists and antimuscarinic drugs have also been demonstrated to inhibit transforming growth factor (TGF)- $\beta 1$-mediated neutrophilic inflammation in COPD [20]. It is known that TGF- $\beta 1$ is increased in induced sputum samples from COPD patients compared with healthy controls and that such samples are able to induce neutrophil adherence to bronchial epithelial cells, which is in part TGF- $\beta 1$ dependent [20]. It is of interest, therefore, that tiotropium bromide has been demonstrated to attenuate neutrophilic inflammation in COPD and that such an effect might be increased by combing with a LABA such as oladaterol [20]. 
These complementary activities have led to LABAs and LAMAs often being used together, particularly in the treatment of patients with COPD [21]. Additionally, it is recognised that these two classes of drug can provide better bronchodilation than using either class of drug alone (as described above), which is part of the justification for using both classes of drug at the same time [21]. Such observations have therefore led to the development of a number of new drugs that have both $\beta_{2}$-agonist activity and muscarinic receptor antagonism in the same molecule, some of which have now reached early clinical development $[10,22]$. These are referred to as bifunctional (or dual-pharmacophore) muscarinic antagonist $/ \beta_{2}$-agonist (MABA) agents, exemplified by the drug GSK 961081, which has recently been shown to induce bronchodilation in patients with COPD that lasts for up to $24 \mathrm{~h}$, and that is comparable to a combination of salmeterol and tiotropium [22, 23]. While there was improvement in lung function, there did not appear to be any interaction at the level of adverse effects, which would appear to one of the potential major advantages of the MABAs over increasing the dose of a single class of bronchodilator. Other examples of MABAs include THRX 200495, AZD 2115, LAS 190792, TEI3252, PF-3429281 and PF-4348235 (table 1).

The MABA approach circumvents the potential problem of formulating different drugs in one inhaler, providing a fixed ratio of muscarinic antagonism and $\beta_{2}$-agonism compared with combination therapy [24]. However, what is not yet clear is the relative contribution of the two different pharmacological activities to the overall improvement in lung function observed, and indeed on which pharmacological action such drugs should be optimally dosed, as some examples of MABAs have different pharmacodynamic half-lives for their $\beta_{2}$-agonist activity and the muscarinic receptor antagonist activity with the same molecule $[24,25]$. However, a recent clinical study has demonstrated that treatment with three separate doses of GSK 961081 (once-daily doses of $100 \mu \mathrm{g}, 400 \mu \mathrm{g}$ or $800 \mu \mathrm{g}$, or twice-daily doses of $100 \mu \mathrm{g}, 200 \mu \mathrm{g}$ or $400 \mu \mathrm{g}$ ) showed superior improvements in lung function in patients with COPD compared with a standard dose of salmeterol ( $50 \mu \mathrm{g}$ twice daily), suggesting that the MABA provides a better treatment than monotherapy with a $\beta_{2}$-agonist [26]. In fact, differences between GSK 961081 doses and salmeterol treatment ranged from $78 \mathrm{~mL}(100 \mu \mathrm{g}$ once daily) to $200 \mathrm{~mL}(800 \mu \mathrm{g}$ once daily), with statistically significant differences in favour of GSK 961081 for all doses tested, except $100 \mu \mathrm{g}$ once daily [26]. To date, however, a similar trial has not yet been performed comparing a MABA with monotherapy with an antimuscarinic drug. Thus, while MABAs show promise, there is much still to be understood as to how best to use these drugs and how they will compare to existing fixed-dose combination inhalers [27].

\section{Bifunctional bronchodilator/anti-inflammatory drugs}

Xanthines such as theophylline have been widely used as treatments for both asthma and COPD for more than 100 years, and while early clinical studies with such drugs have stressed their bronchodilator activity, they were originally introduced into clinical practice to treat an inflammatory renal disease, glomerular nephritis [28]. Early on, it was recognised experimentally that xanthines could exhibit anti-inflammatory activity in the lung, additional to their bronchodilator activity [29], which has now been confirmed clinically by a number of laboratories in patients with asthma [30-34] or COPD [35, 36]. Such observations demonstrated that it was possible to have both bronchodilator and anti-inflammatory activity in a single molecule. However, theophylline is usually administered systemically (orally for maintenance therapy and intravenously for treatment of acute exacerbations) and it is well known as a drug having a narrow therapeutic window [37]. Furthermore, it is now appreciated that higher doses of theophylline are probably required to obtain the bronchodilator activity than the anti-inflammatory activity, albeit that the latter effect is often only seen following chronic treatment [37, 38]. Additionally, the withdrawal of xanthines from patients with asthma or COPD leads to worsening of airway inflammation and symptoms, even in patients taking glucocorticosteroids and other classes of bronchodilator drug [39-41], suggesting that xanthines possess other useful pharmacological properties not shared with glucocorticosteroids or other bronchodilator classes.

There has therefore been an interest in finding safer xanthines over the years, including bamiphylline [42], enprofylline [43], isbufylline [44] and doxophylline [45, 46], some of which have been approved for the treatment of asthma and COPD. Like theophylline, each of these drugs has been shown to possess antiinflammatory and bronchodilator actions to varying degrees, and in the case of doxophylline, a wider therapeutic window than theophylline [45]. However, what still remains unclear is the mechanism(s) of action of xanthines that contributes to their anti-inflammatory and bronchodilator activity.

One prominent mechanism of action proposed for xanthines over the last few decades has been inhibition of phosphodiesterase (PDE) enzymes and theophylline and the related xanthine isobutyl methylxanthine in particular, have often been described as the archetypal nonselective PDE inhibitors [47]. Therefore, one approach to try and improve the therapeutic window of xanthines has been to develop more selective inhibitors of the growing family of PDEs, as it is now recognised that PDE 3 and 4 are found in airway smooth muscle, and PDE 3, 4 and 7 are found in the majority of inflammatory cells thought to be involved 
in the pathogenesis of asthma and COPD [37, 38]. Specifically, the PDE3 isoenzyme is considered to predominate functionally in airway smooth muscle and inhibition of this enzyme, rather than PDE4 inhibition, leads to airway smooth muscle relaxation, whereas the PDE4 isoenzyme is the predominant isoenzyme in the majority of inflammatory cells, including neutrophils, which are implicated in the pathogenesis of COPD, and eosinophils, which characterise inflammation in asthma [37, 38]. As a consequence, a number of PDE4 inhibitors have been shown to have an anti-inflammatory activity clinically $[38,48,49]$, which is thought to contribute to a long-term improvement in lung function and fewer exacerbations in patients with severe COPD, as has been observed with the recently approved PDE4 inhibitor, roflumilast $\mathrm{N}$-oxide $[50,51]$, although the side-effect profile of this drug still limits the wider use of this agent. However, while PDE4 is found in human airway smooth muscle, it is now clear from a number of clinical studies with a variety of PDE4 inhibitors administered either orally [52, 53] or by inhalation [54], that this drug class is not able to induce acute bronchodilation [38]. In contrast, a number of selective PDE3 inhibitors have been shown to be bronchodilators in man $[55,56]$ and, indeed, recently, PDE3 has been documented to be upregulated in airway smooth muscle obtained from patients with asthma [57].

The recognition that PDE4 inhibitors are anti-inflammatory and PDE3 inhibitors are bronchodilators has led to the development of drugs having dual inhibitory activity for both PDE3 and PDE4 in order to obtain both bronchodilator and anti-inflammatory activity in the same molecule. The first of these was zardaverine, which clearly exhibited bronchodilation in patients with asthma, but unfortunately was halted during clinical development because of gastrointestinal side effects [58]. Another example was benzafentrine (AH 21-132) [59], which was also demonstrated to be a bronchodilator, but was later discontinued from clinical development, as was pumafentrine [60].

More recently, some newer compounds having both PDE3 and 4 inhibitory activities have been described, but these have also been stopped at the preclinical stage because of unwanted gastrointestinal side-effects [61]. However, another novel inhaled PDE3/4 inhibitor, RPL 554 [62], has been shown in early clinical studies to have both bronchodilator and anti-inflammatory actions at the same dose without having significant side-effects [63], representing a potentially new class of drug for the treatment of patients with asthma or COPD [64].

A further attempt to combine anti-inflammatory and bronchodilator actions in a single molecule has been to combine the bronchodilator actions of nitric oxide with the anti-inflammatory actions of an ICS. NO-budesonide (TPI 1020) $[65,66]$ was the first example of such a drug, but this drug was dropped from further development because of limited clinical efficacy. Another approach attempted to combine nitric oxide and salbutamol into a single molecule (NCX 950) to obtain both bronchodilator and antiinflammatory actions, which showed some promise pre-clinically [67] (table 1).

GS-5759 is a novel bifunctional PDE4 inhibitor/LABA that displays PDE4 inhibition and $\beta_{2}$-agonism comparable to roflumilast and indacaterol, respectively [68]. More recently, a series of molecules that combine the anti-inflammatory PDE4 inhibitor roflumilast with the LABA salmeterol [68] have been described that is another potential example of a new drug class that combine anti-inflammatory and bronchodilator actions in a single molecule, although to date, there are very limited biological data on these molecules. A potential advantage of these compounds is that both $\beta_{2}$-agonists and PDE4 inhibitors rely on modulation of the second messenger cAMP to elicit their effects, and it is possible that the combination could provide additive or synergistic anti-inflammatory activity in the lung [69]. In addition, bifunctional compounds in which a PDE4 inhibitor is connected to a muscarinic receptor antagonist have been described [70]. All use a pyrazolopyridine as the PDE4 inhibitor and a biaryl-containing muscarinic antagonist, but differ in the linker [71]. Another molecule with such dual activity is UCB-101333-3, a 4,6-diaminopyrimidine [72].

\section{Bifunctional anti-inflammatory drugs}

Glucocorticosteroids are currently recognised as the gold standard anti-inflammatory drugs for the treatment of respiratory diseases, in part because they exhibit a wide range of anti-inflammatory actions, including the activation and recruitment of most inflammatory cell types into the lung [73]. However, this drug class can also be associated with significant side-effects when they enter the systemic circulation, as well as having local side-effects when applied topically. Not surprisingly, therefore, given the success of glucocorticosteroids as anti-inflammatory drugs, it has been the "holy grail" of the pharmaceutical industry for many years to find an alternative anti-inflammatory drug to glucocorticosteroids in the respiratory field, but that have a better safety profile $[73,74]$. There have been many new classes of anti-inflammatory drug developed $[73,74]$, most of which have failed, except in the treatment of a subset of more severe patients with asthma [75] or COPD [51]. Many of these have been drugs or biologics directed against a single 
inflammatory mediator, and these failures [76-79] suggest that the complexity of the inflammatory response in both asthma and COPD requires drugs that have actions at more than one biological target.

Thus, a number of drugs have been developed having bifunctional anti-inflammatory activity, including drugs exhibiting antagonism for the receptors for platelet-activating factor and histamine, and mast cell secretion-blocking effects in the same molecule, such as rupatadine [80, 81]. Another example of bifunctional anti-inflammatory compounds is drugs behaving as thromboxane receptor antagonists and cysteinyl-leukotriene antagonists in the same molecule [82]. However, both of these classes of drug have, to date, only shown limited efficacy, at least in the treatment of allergic airway disease.

There have also been attempts to create bifunctional drugs by dual targeting combinations of cytokines with antibodies. One example is a biologic agent targeting both murine IL-4 and IL-13 that was generated by combining well-characterised binding domains in an optimal configuration, using appropriate linker regions [83]. The bifunctional IL-4 and IL-13 antagonist demonstrated high affinity for both cytokines, and reduced the IL-4-dependent rise in serum IgE, and reduced IL-13-dependent airway hyperresponsiveness, lung inflammation, mucin gene expression and serum chitinase responses in mice. Effective dual blockade of IL-13 and IL-4 resulted in greater therapeutic benefit than was achieved by targeting either cytokine alone [83], and clinical trial results of such an approach are awaited with interest.

\section{Conclusions}

It is now apparent that there is a growing trend to develop drugs with bifunctional activity for the treatment of patients with asthma or COPD. Such drugs have the potential benefit of being easier to formulate than combinations of multiple drugs in a single inhaler, improving adherence and the potential to offer additive or even synergistic benefit, as such drugs may target different cellular compartments than when individual drugs are presented to cells separately. It is also likely that the development of bifunctional drugs may serve as a basis for improved "triple-therapy" fixed-dose combination inhalers through co-formulation that could deliver three complementary therapeutic effects for patients with COPD using only two drugs; for instance, there is recent evidence that the use of the dual PDE3/4 inhibitor RPL554 in combination with an $\mathrm{M}_{3}$ muscarinic antagonist may provide synergistic activity on the relaxation of human airway smooth muscle, which suggests that if this drug was combined with an anticholinergic drug, this could translate into further clinical benefit [84]. Furthermore, the MABA GSK961081 has recently been evaluated as twice-daily, fixed-dose combination with fluticasone propionate [10].

We are of the opinion, therefore, that bifunctional drugs offer an exciting new approach to the treatment of asthma and COPD, where there remains significant unmet need, and such drugs could become highly significant future treatments for patients suffering from these common respiratory diseases.

\section{References}

Boulet L-P, FitzGerald JM, Levy ML, et al. A guide to the translation of the Global Initiative for Asthma (GINA) strategy into improved care. Eur Respir J 2012; 39: 1220-1229.

2 Vestbo J, Hurd SS, Agustí AG, et al. Global strategy for the diagnosis, management, and prevention of chronic obstructive pulmonary disease: GOLD executive summary. Am J Respir Crit Care Med 2013; 187: 347-365.

3 Wald DS, Law M, Morris JK, et al. Combination therapy versus monotherapy in reducing blood pressue: metaanalysis on 11,000 patients from 42 trials. Am J Med 2009; 3: 290-300.

4 van Meir H, Kenter GG, Burggraaf J, et al. The need for improvement of the treatment of advanced and metastatic cervical cancer, the rationale for combined chemo-immunotherapy. Anticancer Agents Med Chem 2013; 14: 190-203.

Flexner C, Saag M. The antiretroviral drug pipeline: prospects and implications for future treatment research. Curr Opin HIV AIDS 2013; 8: 572-578.

6 Dawson R, Diacon A. PA-824, moxifloxacin and pyrazinamide combination therapy for tuberculosis. Expert Opin Investig Drugs 2013; 22: 927-932.

7 Huang Z-B, Zhao S-S, Huang Y, et al. Comparison of the efficacy of lamivudine plus adefovir versus entecavir in the treatment of lamivudine-resistant chronic hepatitis B: a systematic review and meta-analysis. Clin Ther 2013; 35: 1997-2006.

8 Cazzola M, Page CP, Calzetta L, et al. Pharmacology and therapeutics of bronchodilators. Pharmacol Rev 2012; 64: 450-504.

9 Matera MG, Page CP, Cazzola M. Novel bronchodilators for the treatment of chronic obstructive pulmonary disease. Trends Pharmacol Sci 2011; 32: 495-506.

10 Cazzola M, Rogliani P, Segreti A, et al. An update on bronchodilators in Phase I and II clinical trials. Expert Opin Investig Drugs 2012; 21: 1489-1501.

1 Barnes PJ. Triple inhalers for obstructive airways disease: will they be useful? Expert Rev Respir Med 2011; 5: 297-300.

12 Stempel DA, Stoloff SW, Carranza Rosenzweig JR, et al. Adherence to asthma controller medication regimens. Respir Med 2005; 99: 1263-1267.

13 Bateman ED, Hurd SS, Barnes PJ, et al. Global strategy for asthma management and prevention: GINA executive summary. Eur Respir J 2008; 31: 143-178.

14 Cazzola M, Molimard $M$. The scientific rationale for combining long acting $\beta_{2}$ agonists and muscarinic antagonists in COPD. Pulm Pharmacol Ther 2010; 23: 257-267. 
15 Cazzola M, Segreti A, Matera MG. New developments in the combination treatment of COPD: focus on umeclidinium/vilanterol. Drug Des Devel Ther 2013; 7: 1201-1208.

16 Meurs H, Dekkers BG, Maarsingh H, et al. Muscarinic receptors on airway mesenchymal cells: novel findings for an ancient target. Pulm Pharmacol Ther 2013; 26: 145-155.

17 Meurs H, Oenema TA, Kistemaker LE, et al. A new perspective on muscarinic receptor antagonism in obstructive airways diseases. Curr Opin Pharmacol 2013; 13: 316-323.

18 Ahmedat AS, Warnken M, Seemann WK, et al. Pro-fibrotic processes in human lung fibroblasts are driven by an autocrine/paracrine endothelinergic system. Br J Pharmacol 2013; 168: 471-478.

19 Ahmedat AS, Warnken M, Juergens UR, et al. $\beta_{2}$-adrenoceptors and muscarinic receptors mediate opposing effects on endothelin-1 expression in human lung fibroblasts. Eur J Pharmacol 2012; 691: 218-224.

20 Profita M, Bonanno A, Montalbano AM, et al. $\beta_{2}$ long-acting and anticholinergic drugs control TGF- $\beta 1$-mediated neutrophilic inflammation in COPD. Biochim Biophys Acta 2012; 1822: 1079-1089.

21 van der Molen T, Cazzola M. Beyond lung function in COPD management: effectiveness of LABA/LAMA combination therapy on patient-centred outcomes. Prim Care Respir J 2012; 21: 101-108.

22 Bateman ED, Kornmann O, Ambery C, et al. Pharmacodynamics of GSK961081, a bi-functional molecule, in patients with COPD. Pulm Pharmacol Ther 2013; 26: 581-587.

23 Norris V, Ambery C. Bronchodilation and safety of supratherapeutic doses of salbutamol or ipratropium bromide added to single dose GSK961081 in patients with moderate to severe COPD. Pulm Pharmacol Ther 2013; 26: 574-580.

24 Hughes $\mathrm{AD}$, Jones LH. Dual-pharmacology muscarinic antagonist and $\beta_{2}$-agonist molecules for the treatment of chronic obstructive pulmonary disease. Future Med Chem 2011; 3: 1585-1605.

25 McNamara A, Steinfeld T, Pulido-Rios MT, et al. Preclinical efficacy of THRX-200495, a dual pharmacology muscarinic receptor antagonist and $\beta_{2}$-adrenoceptor agonist (MABA). Pulm Pharmacol Ther 2012; 25: 357-363.

26 Wielders PL, Ludwig-Sengpiel A, Locantore N, et al. A new class of bronchodilator improves lung function in COPD: a trial with GSK961081. Eur Respir J 2013; 42: 972-981.

27 Cazzola M, Lopez-Campos JL, Puente-Maestu L. The MABA approach: a new option to improve bronchodilator therapy. Eur Respir J 2013; 42: 885-887.

28 Persson CG. On the medical history of xanthines and other remedies for asthma: a tribute to HH Salter. Thorax 1985; 40: 881-886.

29 Spina D, Landells LJ, Page CP. The role of theophylline and phosphodiesterase4 isoenzyme inhibitors as antiinflammatory drugs. Clin Exp Allergy 1998; 28: Suppl. 3, 24-34.

30 Crescioli S, Spinazzi A, Plebani M, et al. Theophylline inhibits early and late asthmatic reactions induced by allergens in asthmatic subjects. Ann Allergy 1991; 66: 245-251.

31 Sullivan P, Bekir S, Jaffar Z, et al. Anti-inflammatory effects of low-dose oral theophylline in atopic asthma. Lancet 1994; 343: 1006-1008.

32 Jaffar ZH, Sullivan P, Page C, et al. Low-dose theophylline modulates T-lymphocyte activation in allergenchallenged asthmatics. Eur Respir J 1996; 9: 456-462.

33 Evans DJ, Taylor DA, Zetterstrom O, et al. A comparison of low-dose inhaled budesonide plus theophylline and high-dose inhaled budesonide for moderate asthma. New Engl J Med 1997; 337: 1412-1418.

34 Lim S, Tomita K, Caramori G, et al. Low-dose theophylline reduces eosinophilic inflammation but not exhaled nitric oxide in mild asthma. Am J Respir Crit Care Med 2001; 164: 273-276.

35 Culpitt SV, de Matos C, Russell RE, et al. Effect of theophylline on induced sputum inflammatory indices and neutrophil chemotaxis in chronic obstructive pulmonary disease. Am J Respir Crit Care Med 2002; 165: 1371-1376.

36 Ford PA, Durham AL, Russell REK, et al. Treatment effects of low-dose theophylline combined with an inhaled corticosteroid in COPD. Chest 2010; 137: 1338-1344.

37 Boswell-Smith V, Cazzola M, Page CP. Are phosphodiesterase inhibitors just more theophylline? J Allergy Clin Immunol 2006; 117: 1237-1243.

38 Page CP, Spina D. Phosphodiesterase inhibitors in the treatment of inflammatory diseases. Handbook Exp Pharmacol 2011; 204: 391-414.

39 Baba K, Sakakibara A, Yagi T, et al. Effects of theophylline withdrawal in well-controlled asthmatics treated with inhaled corticosteroid. J Asthma 2001; 38: 615-624.

40 Minoguchi K, Kohno Y, Oda N, et al. Effect of theophylline withdrawal on airway inflammation in asthma. Clin Exp Allergy 1998; 28: Suppl. 3, 57-63.

41 Kidney J, Dominguez M, Taylor M, et al. Immunomodulation by theophylline in asthma. Demonstration by withdrawal of therapy. Am J Respir Crit Care Med 1995; 151: 1907-1914.

42 Spinelli A, Fanelli A, Gorini M, et al. Control of breathing in patients with chronic pulmonary obstructive disease: response to bamiphylline. Respiration 1991; 58: 241-248.

43 Pauwels R, Van Renterghem D, Van der Straeten M, et al. The effect of theophylline and enprofylline on allergeninduced bronchoconstriction. J Allergy Clin Immunol 1985; 76: 583-590.

44 Manzini S, Perretti F, Abelli L, et al. Isbufylline, a new xanthine derivative, inhibits airway hyperresponsiveness and airway inflammation in guinea pigs. Eur J Pharmacol 1993; 249: 251-257.

45 Page CP. Doxophylline: a "novophylline". Pulm Pharmacol Ther 2010; 23: 231-234.

46 van Mastbergen J, Jolas T, Allegra L, et al. The mechanism of action of doxofylline is unrelated to HDAC inhibition, PDE inhibition or adenosine receptor antagonism. Pulm Pharmacol Ther 2012; 25: 55-61.

47 Nicholson CD, Challiss RA, Shahid M. Differential modulation of tissue function and therapeutic potential of selective inhibitors of cyclic nucleotide phosphodiesterase isoenzymes. Trends Pharmacol Sci 1991; 12: 19-27.

48 Gamble E, Grootendorst DC, Brightling CE, et al. Anti-inflammatory effects of the phosphodoesterase inhibitor cilomilast (ARIFLO) in chronic obstructive pulmonary disease. Am J Respir Crit Care Med 2003; 168: 976-982.

49 Grootendorst DC, Gauw SA, Verhoosel RM, et al. Reduction in sputum neutrophil and eosinophil numbers by the PDE4 inhibitor roflumilast in patients with COPD. Thorax 2007; 62: 1081-1087.

50 Calverley PMA, Rabe KF, Goehring U-M, et al. Roflumilast in symptomatic chronic obstructive pulmonary disease: two randomised clinical trials. Lancet 2009; 374: 685-694.

51 Fabbri LM, Calverley PMA, Izquierdo-Alonso JL, et al. Roflumilast in moderate-to-severe chronic obstructive pulmonary disease treated with long acting bronchodilators: two randomised clinical trials. Lancet 2009; 374: 695-703. 
Harbinson PL, MacLeod D, Hawksworth R, et al. The effect of a novel orally active selective PDE4 isoenzyme inhibitor (CDP840) on allergen-induced responses in asthmatic subjects. Eur Respir J 1997; 10: 1008-1014.

53 Grootendorst DC, Gauw SA, Benschop N, et al. Efficacy of the novel phosphodiesterase 4 inhibitor BAY 19-8004 on lung function and airway inflammation in asthma and chronic obstructive pulmonary disease (COPD). Pulm Pharmacol Ther 2003; 16: 115-120.

54 Singh D, Petavy F, Macdonald AJ, et al. The inhaled phosphodiesterase 4 inhibitor GSK256066 reduces allergen challenge responses in asthma. Respir Res 2010; 11: 26.

55 Bardin PG, Dorward MA, Lampe FC, et al. Effect of selective phosphodiesterase 3 inhibition on the early and late asthmatic responses to inhaled allergen. Br J Clin Pharmacol 1998; 45: 387-391.

56 Myou S, Fujimura M, Kamio Y, et al. Bronchodilator effect of inhaled olprinone, a phosphodiesterase 3 inhibitor, in asthmatic patients. Am J Respir Crit Care Med 1999; 160: 817-820.

57 Yick CY, Zwinderman AH, Kunst PW, et al. Transcriptome sequencing (RNA-Seq) of human endobronchial biopsies: asthma versus controls. Eur Respir J 2013; 42: 662-670.

58 Brunnée T, Engelstätter R, Steinijans VW, et al. Bronchodilatory effect of inhaled zardaverine, a phosphodiesterase III and IV inhibitor, in patients with asthma. Eur Respir J 1992; 5: 982-985.

59 Foster RW, Rakshi K, Carpenter JR, et al. Trials of the bronchodilator activity of the isoenzyme-selective phosphodiesterase inhibitor $\mathrm{AH} \mathrm{21-132} \mathrm{in} \mathrm{healthy} \mathrm{volunteers} \mathrm{during} \mathrm{a} \mathrm{methacholine} \mathrm{challenge} \mathrm{test.} \mathrm{Br} J \mathrm{Clin}$ Pharmacol 1992; 34: 527-534.

60 Rieder F, Siegmund B, Bundschuh DS, et al. The selective phosphodiesterase 4 inhibitor roflumilast and phosphodiesterase $3 / 4$ inhibitor pumafentrine reduce clinical score and TNF expression in experimental colitis in mice. PLoS One 2013; 8: e56867.

61 Ochiai K, Takita S, Kojima A, et al. Phosphodiesterase inhibitors. Part 5: hybrid PDE3/4 inhibitors as dual bronchorelaxant/anti-inflammatory agents for inhaled administration. Bioorg Med Chem Lett 2013; 23: 375-381.

62 Boswell-Smith V, Spina D, Oxford AW, et al. The pharmacology of two novel long-acting phosphodiesterase 3/4 inhibitors, RPL554 [9,10-dimethoxy-2(2,4,6-trimethylphenylimino)-3-( $N$-carbamoyl-2-aminoethyl)-3,4,6,7-tetrahydro$2 \mathrm{H}$-pyrimido[6,1-a] isoquinolin-4-one] and RPL565 [6,7-dihydro-2-(2,6-diisopropylphenoxy)-9,10-dimethoxy-4Hpyrimido[6,1-a] isoquinolin-4-one]. J Pharmacol Exp Ther 2006; 318: 840-848.

63 Franciosi LG, Diamant Z, Banner KH, et al. Efficacy and safety of RPL 554, a dual PDE3 and PDE4 inhibitor, in healthy volunteers and in patients with asthma or chronic obstructive pulmonary disease: findings from four clinical trials. Lancet Respir Med 2013; 1: 714-727.

64 Wedzicha JA. Dual PDE3/4 inhibition: a novel approach to airway disease? Lancet Respir Med 2013; 1: 669-670.

65 Boulet L-P, Lemière C, Gauvreau G, et al. Safety, pharmacodynamics and pharmacokinetics of TPI 1020 in smokers with asthma. Respir Med 2009; 103: 1159-1166.

66 Turner DL, Ferrari N, Ford WR, et al. TPI 1020, a novel anti-inflammatory, nitric oxide donating compound, potentiates the bronchodilator effects of salbutamol in conscious guinea-pigs. Eur J Pharmacol 2010; 641: 213-219.

67 Lagente V, Naline E, Guenon I, et al. A nitric oxide-releasing salbutamol elicits potent relaxant and antiinflammatory activities. J Pharmacol Exp Ther 2004; 310: 367-375.

68 Tannheimer SL, Sorenson EA, Cui Z-H, et al. The in vitro pharmacology of GS-5759, a novel bifunctional phosphodiesterase 4 inhibitor and long acting $\beta_{2}$-adrenoceptor agonist. J Pharmacol Exp Ther 2014; 349: 85-93.

69 Liu A, Huang L, Wang Z, et al. Hybrids consisting of the pharmacophores of salmeterol and roflumilast or phthalazinone: dual $\beta_{2}$-adrenoceptor agonists-PDE4 inhibitors for the treatment of COPD. Bioorg Med Chem Lett 2013; 23: 1548-1552.

70 Tannheimer SL, Sorensen EA, Haran AC, et al. Additive anti-inflammatory effects of beta 2 adrenoceptor agonists or glucocorticosteroid with roflumilast in human peripheral blood mononuclear cells. Pulm Pharmacol Ther 2012; 25: $178-184$

71 Phillips G, Salmon M. Bifunctional compounds for the treatment of COPD. Ann Rep Med Chem 2012; 47: 209-222

72 Provins L, Christophe B, Danhaive P, et al. Dual $\mathrm{M}_{3}$ antagonists-PDE4 inhibitors. Part 2: synthesis and SAR of 3substituted azetidinyl derivatives. Bioorg Med Chem Lett 2007; 17: 3077-3080.

73 Adcock IM, Caramori G, Chung KF. New targets for drug development in asthma. Lancet 2008; $372: 1073-1087$. Cazzola M, Page CP, Calzetta L, et al. Emerging anti-inflammatory strategies for COPD. Eur Respir J 2012; 40: 724-741. Nair P, Pizzichini MM, Kjarsgaard M, et al. Mepolizumab for prednisone-dependent asthma with sputum eosinophilia. N Engl J Med 2009; 360: 985-993.

76 Bryan SA, O'Connor BJ, Matti S, et al. Effects of recombinant human interleukin-12 on eosinophils, airway hyperresponsiveness, and the late asthmatic response. Lancet 2000; 356: 2149-2153.

77 Leckie MJ, ten Brinke A, Khan J, et al. Effects of an interleukin-5 blocking monoclonal antibody on eosinophils, airway hyper-responsiveness, and the late asthmatic response. Lancet 2000; 356: 2144-2148.

78 Nair P, Gaga M, Zervas E, et al. Safety and efficacy of a CXCR2 antagonist in patients with severe asthma and sputum neutrophils: a randomized, placebo-controlled clinical trial. Clin Exp Allergy 2012; 42: 1097-1103.

79 Gauvreau GM, Boulet L-P, Cockcroft DW, et al. OX40L blockade and allergen-induced airway responses in subjects with mild asthma. Clin Exp Allergy 2014; 44: 29-37.

80 Saint-Martin F, Dumur JP, Pérez I, et al. A randomized, double-blind, parallel-group study, comparing the efficacy and safety of rupatadine (20 and $10 \mathrm{mg}$ ), a new PAF and $\mathrm{H} 1$ receptor-specific histamine antagonist, to loratadine $10 \mathrm{mg}$ in the treatment of seasonal allergic rhinitis. J Investig Allergol Clin Immunol 2004; 14: 34-40.

81 Church MK. Efficacy and tolerability of rupatadine at four times the recommended dose against histamine- and platelet-activating factor-induced flare responses and ex vivo platelet aggregation in healthy males. Br J Dermatol 2010; 163: 1330-1332.

82 Arakida Y, Suwa K, Ohga K, et al. In vitro pharmacologic profile of YM158, a new dual antagonist for LTD4 and TXA2 receptors. J Pharmacol Exp Ther 1998; 287: 633-639.

83 Kasaian MT, Marquette K, Fish S, et al. An IL-4/IL-13 dual antagonist reduces lung inflammation, airway hyperresponsiveness, and IgE production in mice. Am I Respir Cell Mol Biol 2013; 49: 37-46.

84 Calzetta L, Page CP, Spina D, et al. Effect of the mixed phosphodiesterase 3/4 inhibitor RPL554 on human isolated bronchial smooth muscle tone. J Pharmacol Exp Ther 2013; 346: 414-423. 